\title{
Risk of severe COVID-19 disease with ACE inhibitors and angiotensin receptor blockers: cohort study including 8.3 million people
}

\author{
Julia Hippisley-Cox (1) , ${ }^{1}$ Duncan Young, ${ }^{2,3}$ Carol Coupland, ${ }^{4}$ Keith M Channon, ${ }^{5}$ \\ Pui San Tan, ${ }^{6}$ David A Harrison 0 (1) ${ }^{7}$ Kathryn Rowan, ${ }^{8}$ Paul Aveyard, ${ }^{6}$ Ian D Pavord, ${ }^{9}$ \\ Peter J Watkinson (10) 5,10
}

For numbered affiliations see end of article.

\section{Correspondence to}

Prof Julia Hippisley-Cox, Primary Care Health Sciences, University of Oxford, Oxford OX1 2JD, UK; Julia.Hippisley-Cox@phc.ox. ac.uk

Received 20 May 2020 Revised 8 July 2020 Accepted 13 July 2020 Published Online First 31 July 2020

- http://dx.doi.org/10.1136/ heartjnl-2020-317486

Check for updates

(C) Author(s) (or their employer(s)) 2020. Re-use permitted under CC BY. Published by BMJ.

To cite: Hippisley-Cox J, Young D, Coupland C, et al. Heart 2020;106:1503-1511.

\section{ABSTRACT}

Background There is uncertainty about the associations of angiotensive enzyme (ACE) inhibitor and angiotensin receptor blocker (ARB) drugs with COVID-19 disease. We studied whether patients prescribed these drugs had altered risks of contracting severe COVID-19 disease and receiving associated intensive care unit (ICU) admission.

Methods This was a prospective cohort study using routinely collected data from 1205 general practices in England with 8.28 million participants aged $20-99$ years. We used Cox proportional hazards models to derive adjusted HRs for exposure to ACE inhibitor and ARB drugs adjusted for sociodemographic factors, concurrent medications and geographical region. The primary outcomes were: (a) COVID-19 RT-PCR diagnosed disease and (b) COVID-19 disease resulting in ICU care.

Findings Of 19486 patients who had COVID-19 disease, 1286 received ICU care. ACE inhibitors were associated with a significantly reduced risk of COVID-19 disease (adjusted HR $0.71,95 \% \mathrm{Cl} 0.67$ to 0.74 ) but no increased risk of ICU care (adjusted HR 0.89, $95 \% \mathrm{Cl} 0.75$ to 1.06 ) after adjusting for a wide range of confounders. Adjusted HRs for ARBs were $0.63(95 \% \mathrm{Cl}$ 0.59 to 0.67$)$ for COVID-19 disease and $1.02(95 \% \mathrm{Cl}$ 0.83 to 1.25$)$ for ICU care.

There were significant interactions between ethnicity and ACE inhibitors and ARBs for COVID-19 disease. The risk of COVID-19 disease associated with ACE inhibitors was higher in Caribbean (adjusted HR 1.05, 95\% Cl 0.87 to 1.28 ) and Black African (adjusted HR $1.31,95 \% \mathrm{Cl}$ 1.08 to 1.59 ) groups than the white group (adjusted HR $0.66,95 \% \mathrm{Cl} 0.63$ to 0.70 ). A higher risk of COVID-19 with ARBs was seen for Black African (adjusted HR 1.24, $95 \% \mathrm{Cl} 0.99$ to 1.58 ) than the white (adjusted HR 0.56, $95 \% \mathrm{Cl} 0.52$ to 0.62 ) group.

Interpretation ACE inhibitors and ARBs are associated with reduced risks of COVID-19 disease after adjusting for a wide range of variables. Neither ACE inhibitors nor ARBs are associated with significantly increased risks of receiving ICU care. Variations between different ethnic groups raise the possibility of ethnic-specific effects of ACE inhibitors/ARBs on COVID-19 disease susceptibility and severity which deserves further study.

\section{INTRODUCTION}

The first cases of infection caused by severe acute respiratory syndrome coronavirus 2 (SARS-CoV-2)
(COVID-19) in the UK were confirmed on 24 January 2020. Since then the disease has spread rapidly through the population. There are no vaccines, preventative or curative treatments for COVID-19 disease and only one possible diseasemodifying treatment ${ }^{1}$ so the government has used social distancing as a population-level intervention to limit the rate of increase in cases.

Case series of confirmed COVID-19 have identified age ${ }^{2}$ sex ${ }^{3}$ comorbidities $^{24}$ and ethnicity ${ }^{5}$ as potentially important risk factors for susceptibility to infection, hospitalisation or death due to infection. In addition, chronic use of some medications at the time of exposure has been suggested as a potential risk factor for infection or severe adverse outcomes due to infection, ${ }^{6}$ although the evidence is currently too limited to confirm or refute these concerns. ${ }^{7}$ Understanding this chronic medication use is important because medications could be modified in individuals or at a population scale to alter the likelihood of infection or adverse outcomes. Furthermore, associations between medications and improved outcomes, if confirmed from large cohorts, could provide a basis for rapid prioritisation in prospective randomised clinical trials, and might provide important insights into disease mechanisms and pathogenesis.

SARS-CoV-1 and SARS-CoV-2, which have been responsible for the SARS epidemic and for the COVID-19 pandemic, respectively, interface with the renin-angiotensin-aldosterone system (RAAS) through ACE2, an enzyme that modulates the effects of the RAAS but is also the primary receptor for both SARS viruses. The interaction between the SARS viruses and ACE2 may be one determinant of their infectivity, and there are concerns that RAAS inhibitors may change ACE2 expression and hence COVID-19 virulence. This hypothesis has been extensively reviewed. ${ }^{7}$

ACE inhibitors and angiotensin receptor blocker (ARB) drugs are recommended by the National Institute for Health and Care Excellence as firstline treatment for patients under 55 years of age with hypertension and second-line treatment for those over 55 years of age and for those of African descent. ${ }^{8}$ ACE inhibitors are also widely used to treat congestive cardiac failure. Uncertainty around possible associations of these drugs with COVID-19 disease, and the subsequent risk that patients might 
stop taking these drugs of proven effectiveness, has led to regulatory and professional bodies issuing statements urging patients to keep taking their regular medications. ${ }^{9}$

Although several studies have considered the effect in hospitalised patients of drugs acting on the renin-angiotensin on disease course, ${ }^{6} 1011$ none has looked at population use of these drugs to determine if they modulate susceptibility. We report a large, population-based study where we examined the drug histories of approximately $20 \%$ of all patients tested positive for coronavirus in England to determine if there was an independent association between ACE inhibitor and ARB drug prescription and severe COVID-19 disease susceptibility and progression.

\section{METHODS}

\section{Study design, sources of data and participants}

We undertook a large, open cohort study of all patients aged 20-99 years registered with 1205 general practices in England contributing to the QResearch database (V.44, uploaded 24 March 2020) linked to COVID-19 RT-PCR test records (updated until 26 April 2020) and with intensive care records (updated until 27 April 2020). The protocol is published. ${ }^{12}$

\section{Primary care data and linked databases}

We included general practices in England contributing to the QResearch database from which current data were available. QResearch is a high-quality research database established in 2002, which has been extensively used for pharmaco-epidemiological research. ${ }^{13}$ QResearch is the largest and most representative General Practitioner (GP) practice research database nationally. ${ }^{14}$

Two national databases were linked to QResearch. The first was the national registry of COVID-19 RT-PCR test positive results held by Public Health England (PHE). Since COVID-19 is a notifiable disease, laboratories in England are required to send results of all tests to PHE. At the time of analysis, 106529 positive COVID-19 test results were available from 106507 individuals in England, until 26 April 2020, of whom 104665 were aged 20-99 years. Of these, 19486 (18.6\%) were linked to QResearch patients.

The second linked database was the Intensive Care National Audit and Research Centre (ICNARC) Case Mix Programme (CMP) database. This is a high-quality, clinical research database which includes contemporaneous data from 285 ICUs in England, Wales and Northern Ireland and is widely used for cohort studies, comparative audit and outcome data ascertainment for randomised clinical trials. ${ }^{15} 16$ As of 28 April 2020, there were 6968 patients admitted for ICU care with COVID-19 disease, of whom 6963 were aged 20-99 years. Of these, 1286 (18.5\%) were linked to QResearch.

\section{Participants}

We identified a cohort consisting of all patients aged 20-99 years who were fully registered with the GP practices on the start date (1 January 2020). Patients entered the cohort on this date and were censored at the earliest of the date of death, leaving the GP practice, the study end date (27 April 2020) or occurrence of the relevant outcomes of interest. We used all the relevant patients on the pooled database to maximise power and to enhance generalisability of the results.

\section{Outcomes}

During our study period, over $98.6 \%$ of all COVID-19 RT-PCR tests in England were undertaken in a hospital setting for symptomatic patients sufficiently unwell to warrant hospital assessment and admission.

Our main outcomes for these analyses were:
1. COVID-19 RT-PCR test positive disease.

2. COVID-19-related admission for ICU care.

\section{Primary exposure variables}

We had two main exposures of interest:

1. ACE inhibitors.

2. ARBs.

We classified a patient as having had exposure to either medication if they had three or more prescriptions, including a prescription issued in the 90 days preceding cohort entry.

\section{Explanatory variables}

We extracted data from the GP record for explanatory and potential confounding variables including variables with some evidence of being risk factors for COVID-19 disease or severe disease as measured by ICU admission and variables likely to influence prescribing of ACE inhibitors and ARB medications. We used the latest information recorded in the GP record on or before study entry as follows:

1. Age $(<40 ; 40-49 ; 50-59 ; 60-69 ; 70-79 ; 80+$ years).

2. Ethnicity (nine categories-white and not recorded, Indian, Pakistani, Bangladeshi, other Asian, Black Caribbean, Black African, Chinese, other)

3. Deprivation quintiles (as measured by the Townsend score where quintile 1 is the most affluent and 5 is the most deprived).

4. Geographical region within England, categorised into 10 groups.

5. Body mass index $\left(\mathrm{kg} / \mathrm{m}^{2}\right)$, categorised into five categoriesunderweight $\left(<20 \mathrm{~kg} / \mathrm{m}^{2}\right)$; normal weight $\left(20-24.9 \mathrm{~kg} / \mathrm{m}^{2}\right)$; overweight $\left(25-29.9 \mathrm{~kg} / \mathrm{m}^{2}\right)$; obese $\left(30-34.9 \mathrm{~kg} / \mathrm{m}^{2}\right)$; severely obese $\left(>35 \mathrm{~kg} / \mathrm{m}^{2}\right)$.

6. Smoking status in five categories-never-smoker; exsmoker; light smoker (1-9 cigarettes/day); moderate smoker (10-19 cigarettes/day); heavy smoker (20+ cigarettes/ day).

7. GP recorded diagnosis of type 1 or type 2 diabetes.

8. GP recorded diagnosis of cardiovascular disease.

9. GP recorded diagnosis of congestive cardiac failure.

10. GP recorded diagnosis of hypertension.

11. GP recorded diagnosis of atrial fibrillation.

12. GP recorded diagnosis of asthma.

13. GP recorded diagnosis of chronic obstructive pulmonary disease.

14. GP recorded diagnosis of chronic kidney disease (CKD stage 3,4 or 5 ).

We also extracted medication use for the following classes of drugs as potential confounding variables. We focused on classes of drugs rather than individual drugs to ensure adequate power. We classified patients as exposed using the same definitions as ACE inhibitors and ARBs.

1. Drugs to treat type 2 diabetes including sulfonylureas, biguanides and other drugs (thiazolidinediones, gliptins, sodium glucose co-transporter 2 inhibitors, glucagon-like peptide- 1 receptor agonists, meglitinides).

2. Anticoagulant drugs (warfarin and direct oral anticoagulants).

3. Antiplatelet drugs.

4. Calcium channel blocking drugs.

5. Thiazides.

6. Potassium-sparing diuretics.

7. Statins. 


\section{Statistical analyses}

After conducting univariable analyses, we conducted a multivariable analysis based on patients with complete data. We then used multiple imputation with chained equations to replace missing values for ethnicity, body mass index and smoking status and used these values in our main analyses. ${ }^{17}$ We included all exposure and explanatory variables in the imputation model, along with the Nelson-Aalen estimator of the baseline cumulative hazard, and the outcome indicator. We carried out five imputations. We used Cox's proportional hazards models to estimate adjusted HRs for ACE inhibitors and ARBs adjusting for the confounders. We tested for interactions between ACE inhibitors, ARBs and ethnicity.

We undertook several sensitivity analyses. To further reduce indication biases, additional analyses restricted to patients with hypertension or heart failure to directly compare risks for ACE inhibitors and ARBs with other antihypertensive drugs. We also undertook analyses adjusted for the number of antihypertensive drugs as a proxy for severity of hypertension (untreated hypertension; monotherapy; dual therapy; triple or more therapy). Lastly, we changed the definition of exposure to requiring a prescription within the last 30 days prior to cohort entry. We used $\mathrm{p}<0.01$ (two-tailed) to determine statistical significance, to take account of multiple testing.

\section{Patient and public involvement}

Patient representatives from the QResearch Advisory Board have advised the whether to undertake this research, on the data linkage, public interest and likely public benefit resulting from the study, dissemination of studies using QResearch data, including the use of lay summaries describing the research and its findings.

\section{RESULTS}

\section{Overall study population}

One thousand two hundred five QResearch practices were included in our analysis. Of the 10594500 patients registered on 1 January 2020, 8275949 were aged between 20 and 99 years. Of these, $19486(0.24 \%)$ had a COVID-19 RT-PCR positive result and 1286 were admitted to an ICU.

\section{Baseline characteristics}

Table 1 shows the baseline characteristics of the overall cohort consisting of 8275949 patients. The median age was 47 years (IQR 33-62); self-assigned ethnicity was recorded in 6691660 (80.9\%). A total of 645577 patients (7.8\% of 8275949$)$ were currently prescribed an ACE inhibitor and 308881 (3.7\%) were currently prescribed an ARB drug. Table 2 shows the proportions of patients prescribed ACE inhibitors and ARBs by ethnicity and other characteristics.

Figure $1 \mathrm{~A}$ and $\mathrm{B}$ show adjusted HRs for each outcome based on the multiply-imputed data. Figure $2 \mathrm{~A}$ and $\mathrm{B}$ show the same for the complete case analysis.

\section{Associations of each outcome with the primary exposures of interest: ACE inhibitor and ARB medication}

ACE inhibitors were associated with a significantly reduced risk of COVID-19 disease requiring hospital admission (adjusted HR $0.71,95 \%$ CI 0.67 to 0.74 ) but were not significantly associated with risk of ICU care (adjusted HR $0.89,95 \%$ CI 0.75 to 1.06) after adjusting for a wide range of confounders. Adjusted HRs for ARBs were 0.63 (95\% CI 0.59 to 0.67 ) for COVID-19 disease and 1.02 (95\% CI 0.83 to 1.25 ) for ICU care. The results
Table 1 Baseline characteristics of men and women aged 20-99 years registered with QResearch practices on 1 January 2020 and characteristics of patients with each of the two primary outcomes

\begin{tabular}{|c|c|c|c|}
\hline Category & $\begin{array}{l}\text { Total population } \\
\text { (column \%) }\end{array}$ & $\begin{array}{l}\text { COVID-19 } \\
\text { positive } \\
\text { (column \%) }\end{array}$ & $\begin{array}{l}\text { COVID-19 ICU } \\
\text { admission } \\
\text { (column \%) }\end{array}$ \\
\hline Total population & 8275949 & 19486 & 1286 \\
\hline Male & $4115973(49.73)$ & $9376(48.12)$ & $940(73.09)$ \\
\hline \multicolumn{4}{|l|}{ Age (years) } \\
\hline Mean age (SD) & $48.47(18.41)$ & $62.18(20.84)$ & $59.19(12.52)$ \\
\hline $20-39$ & 3135980 (37.89) & $3487(17.89)$ & $95(7.39)$ \\
\hline $40-49$ & 1399562 (16.91) & $2474(12.70)$ & $159(12.36)$ \\
\hline $50-59$ & $1386093(16.75)$ & $2927(15.02)$ & $366(28.46)$ \\
\hline $60-69$ & $1037077(12.53)$ & $2462(12.63)$ & 387 (30.09) \\
\hline 70-79 & $802224(9.69)$ & $2734(14.03)$ & $242(18.82)$ \\
\hline $80+$ years & $515013(6.22)$ & $5402(27.72)$ & $37(2.88)$ \\
\hline \multicolumn{4}{|l|}{ Material deprivation } \\
\hline Quintile 1 (most affluent) & $1877761(22.69)$ & $3834(19.68)$ & $214(16.64)$ \\
\hline Quintile 2 & 1819942 (21.99) & $3970(20.37)$ & $215(16.72)$ \\
\hline Quintile 3 & $1671924(20.20)$ & $4205(21.58)$ & $237(18.43)$ \\
\hline Quintile 4 & $1490725(18.01)$ & 3846 (19.74) & $248(19.28)$ \\
\hline Quintile 5 (most deprived) & $1415597(17.10)$ & $3631(18.63)$ & $372(28.93)$ \\
\hline Ethnicity recorded & $6691660(80.86)$ & $16379(84.06)$ & $1111(86.39)$ \\
\hline White/not recorded & $6960062(84.10)$ & 14976 (76.86) & $788(61.28)$ \\
\hline Indian & $228467(2.76)$ & $847(4.35)$ & $66(5.13)$ \\
\hline Pakistani & $147397(1.78)$ & $399(2.05)$ & $48(3.73)$ \\
\hline Bangladeshi & $110368(1.33)$ & $256(1.31)$ & $44(3.42)$ \\
\hline Other Asian & $146174(1.77)$ & 661 (3.39) & $70(5.44)$ \\
\hline Caribbean & $93949(1.14)$ & $557(2.86)$ & 59 (4.59) \\
\hline Black African & $199200(2.41)$ & $812(4.17)$ & $106(8.24)$ \\
\hline Chinese & $82984(1.00)$ & $87(0.45)$ & $12(0.93)$ \\
\hline Other ethnic group & $307348(3.71)$ & $891(4.57)$ & $93(7.23)$ \\
\hline \multicolumn{4}{|l|}{ Geographical region } \\
\hline East Midlands & $216535(2.62)$ & $238(1.22)$ & $13(1.01)$ \\
\hline East of England & $296236(3.58)$ & $562(2.88)$ & $19(1.48)$ \\
\hline London & $2080923(25.14)$ & $6059(31.09)$ & $588(45.72)$ \\
\hline North East & $194027(2.34)$ & $600(3.08)$ & $26(2.02)$ \\
\hline North West & 1471787 (17.78) & $4042(20.74)$ & $220(17.11)$ \\
\hline South Central & $1104114(13.34)$ & $2600(13.34)$ & $123(9.56)$ \\
\hline South East & $927208(11.20)$ & $1982(10.17)$ & $119(9.25)$ \\
\hline South West & $899722(10.87)$ & $1055(5.41)$ & $52(4.04)$ \\
\hline West Midlands & $781297(9.44)$ & $1759(9.03)$ & $95(7.39)$ \\
\hline Yorkshire and Humber & $304100(3.67)$ & $589(3.02)$ & $31(2.41)$ \\
\hline \multicolumn{4}{|l|}{ Smoking status } \\
\hline Never smoker & 4745455 (57.34) & $12036(61.77)$ & 791 (61.51) \\
\hline Ex-smoker & $1774275(21.44)$ & $5715(29.33)$ & $427(33.20)$ \\
\hline Light smoker & $1109154(13.40)$ & $1102(5.66)$ & $47(3.65)$ \\
\hline Moderate smoker & $213629(2.58)$ & $155(0.80)$ & $7(0.54)$ \\
\hline Heavy smoker & $98748(1.19)$ & $97(0.50)$ & $2(0.16)$ \\
\hline Smoking not recorded & $334688(4.04)$ & 381 (1.96) & $12(0.93)$ \\
\hline \multicolumn{4}{|l|}{ Body mass index (BMI) } \\
\hline $\mathrm{BMI}<20 \mathrm{~kg} / \mathrm{m}^{2}$ & $543347(6.57)$ & $1076(5.52)$ & $13(1.01)$ \\
\hline BMI $20-24.99 \mathrm{~kg} / \mathrm{m}^{2}$ & $2438268(29.46)$ & $4913(25.21)$ & $165(12.83)$ \\
\hline BMI $25-29.99 \mathrm{~kg} / \mathrm{m}^{2}$ & $2344187(28.33)$ & $5925(30.41)$ & $410(31.88)$ \\
\hline BMI $30-34.99 \mathrm{~kg} / \mathrm{m}^{2}$ & $1090042(13.17)$ & $3435(17.63)$ & $341(26.52)$ \\
\hline BMI $35+\mathrm{kg} / \mathrm{m}^{2}$ & $619487(7.49)$ & $2409(12.36)$ & $294(22.86)$ \\
\hline BMI not recorded & 1240618 (14.99) & $1728(8.87)$ & $63(4.90)$ \\
\hline \multicolumn{4}{|l|}{ Concurrent morbidity } \\
\hline Chronic renal disease & $338693(4.09)$ & $3442(17.66)$ & $152(11.82)$ \\
\hline Asthma & 1089645 (13.17) & $2764(14.18)$ & $178(13.84)$ \\
\hline COPD & $195115(2.36)$ & $1421(7.29)$ & $46(3.58)$ \\
\hline
\end{tabular}

Continued 


\begin{tabular}{|c|c|c|c|}
\hline Category & $\begin{array}{l}\text { Total population } \\
\text { (column \%) }\end{array}$ & $\begin{array}{l}\text { COVID-19 } \\
\text { positive } \\
\text { (column \%) }\end{array}$ & $\begin{array}{l}\text { COVID-19 ICU } \\
\text { admission } \\
\text { (column \%) }\end{array}$ \\
\hline Cardiovascular disease & $433631(5.24)$ & $3552(18.23)$ & $141(10.96)$ \\
\hline Atrial fibrillation & $201911(2.44)$ & $1870(9.60)$ & $41(3.19)$ \\
\hline Congestive cardiac failure & $97118(1.17)$ & $1211(6.21)$ & $25(1.94)$ \\
\hline Type 1 diabetes & $39094(0.47)$ & $208(1.07)$ & $23(1.79)$ \\
\hline Type 2 diabetes & $536516(6.48)$ & $4027(20.67)$ & $379(29.47)$ \\
\hline Hypertension diagnosis & $1414021(17.09)$ & 7585 (38.93) & $584(45.41)$ \\
\hline No medication & $256762(3.10)$ & $1804(9.26)$ & $93(7.23)$ \\
\hline Monotherapy & $773675(9.35)$ & $3754(19.27)$ & 249 (19.36) \\
\hline Dual therapy & $516178(6.24)$ & $2540(13.03)$ & $215(16.72)$ \\
\hline Triple therapy & $190856(2.31)$ & $1005(5.16)$ & $119(9.25)$ \\
\hline \multicolumn{4}{|l|}{ Long-term medication } \\
\hline ACE inhibitor & $645577(7.80)$ & $2864(14.70)$ & $266(20.68)$ \\
\hline ARB & $308881(3.73)$ & $1417(7.27)$ & $154(11.98)$ \\
\hline Beta-blockers & $525149(6.35)$ & $3185(16.35)$ & $170(13.22)$ \\
\hline Calcium channel blockers & $654171(7.90)$ & $3293(16.90)$ & $353(27.45)$ \\
\hline Other diabetes drugs & $151074(1.83)$ & $1183(6.07)$ & $148(11.51)$ \\
\hline Sulfonylureas & $98908(1.20)$ & 808 (4.15) & $110(8.55)$ \\
\hline Biguanides & $328387(3.97)$ & $2135(10.96)$ & $262(20.37)$ \\
\hline Anticoagulants & $207061(2.50)$ & $1872(9.61)$ & $43(3.34)$ \\
\hline Antiplatelets & $410816(4.96)$ & $3049(15.65)$ & $172(13.37)$ \\
\hline Statins & 1073039 (12.97) & $5616(28.82)$ & $487(37.87)$ \\
\hline Thiazides & $220143(2.66)$ & $803(4.12)$ & $96(7.47)$ \\
\hline Potassium-sparing diuretics & $46825(0.57)$ & $417(2.14)$ & $11(0.86)$ \\
\hline
\end{tabular}

Values are number (\%) of patients unless indicated otherwise.

$A R B$, angiotensin receptor blocker; COPD, chronic obstructive pulmonary disease; ICU, intensive care unit.

were similar, when the proxy measure of hypertension severity was included with adjusted HRs of COVID-19 disease for ACE inhibitors of 0.87 (95\% CI 0.72 to 1.05$)$ and 0.82 (0.68 to 0.99$)$ for ARB.

The results were similar when restricted to patients who had either hypertension or congestive cardiac failure. The adjusted HRs of COVID-19 disease requiring hospital admission associated with ACE inhibitors in this group was 0.69 (95\% CI 0.65 to 0.73 ) and ICU admission was 0.96 (95\% CI 0.78 to 1.16$)$. The corresponding adjusted HRs for ARBs were 0.65 (95\% CI 0.61 to 0.69 ) and 1.14 (95\% CI 0.91 to 1.42 ).

There were significant interactions with ethnicity for ACE inhibitors and ARB (both $\mathrm{p}<0.001$ ) for the COVID-19 RT-PCR diagnosed disease outcome. Table 3 shows the adjusted HRs for ACE inhibitor and ARB use for each of the ethnic groups. For ACE inhibitors the risks of COVID-19 disease were significantly higher in the Caribbean and Black African groups than the white group, with a significantly increased risk in the Black African group (adjusted HR 1.31, 95\% CI 1.08 to 1.59), although the CIs were wide in the non-white ethnic groups. The risks associated with ARB use were significantly higher in the other Asian, Black African, Chinese and other ethnic group than the white group.

\section{Association of each outcome with age, sex, deprivation and ethnicity}

While men were at no greater risk of having COVID-19 diagnosed disease requiring hospital admission than women (adjusted HR 1.02, 95\% CI 0.99 to 1.05), they had a threefold increased risk of ICU admission despite adjustment for confounders (figure 1B). People from the most deprived areas
Table 2 Numbers and proportions of patients taking ACE inhibitor or ARB medication according to patient characteristics

\begin{tabular}{|c|c|c|c|}
\hline Category & $\begin{array}{l}\text { Number in } \\
\text { category }\end{array}$ & $\begin{array}{l}\text { Prescribed ACE } \\
\text { inhibitor (row \%) }\end{array}$ & $\begin{array}{l}\text { Prescribed ARB } \\
\text { (row \%) }\end{array}$ \\
\hline Total population & 8275949 & $645577(7.80)$ & 308881 (3.73) \\
\hline Male & 4115973 & 375509 (9.12) & $145181(3.53)$ \\
\hline Female & 4159976 & 270068 (6.49) & $163700(3.94)$ \\
\hline \multicolumn{4}{|l|}{ Age (years) } \\
\hline $20-39$ & 3135980 & $10921(0.35)$ & $3635(0.12)$ \\
\hline $40-49$ & 1399562 & $44117(3.15)$ & $14746(1.05)$ \\
\hline $50-59$ & 1386093 & $125971(9.09)$ & $46885(3.38)$ \\
\hline $60-69$ & 1037077 & $163430(15.76)$ & $74343(7.17)$ \\
\hline 70-79 & 802224 & 176435 (21.99) & $95393(11.89)$ \\
\hline $80+$ & 515013 & $124703(24.21)$ & $73879(14.35)$ \\
\hline \multicolumn{4}{|l|}{ Material deprivation } \\
\hline Quintile 1 (most affluent) & 1877761 & $177329(9.44)$ & $92484(4.93)$ \\
\hline Quintile 2 & 1819942 & $161223(8.86)$ & $80220(4.41)$ \\
\hline Quintile 3 & 1671924 & $130505(7.81)$ & $60006(3.59)$ \\
\hline Quintile 4 & 1490725 & $101993(6.84)$ & $44660(3.00)$ \\
\hline Quintile 5 (most deprived) & 1415597 & $74527(5.26)$ & $31511(2.23)$ \\
\hline \multicolumn{4}{|l|}{ Ethnicity } \\
\hline White/not recorded & 6960062 & $575787(8.27)$ & $264990(3.81)$ \\
\hline Indian & 228467 & $14185(6.21)$ & $9936(4.35)$ \\
\hline Pakistani & 147397 & $10198(6.92)$ & $5656(3.84)$ \\
\hline Bangladeshi & 110368 & $8189(7.42)$ & $4134(3.75)$ \\
\hline Other Asian & 146174 & $8000(5.47)$ & $5259(3.60)$ \\
\hline Caribbean & 93949 & 7478 (7.96) & $5358(5.70)$ \\
\hline Black African & 199200 & 9379 (4.71) & $6017(3.02)$ \\
\hline Chinese & 82984 & 1460 (1.76) & $1112(1.34)$ \\
\hline Other ethnic group & 307348 & $10901(3.55)$ & $6419(2.09)$ \\
\hline \multicolumn{4}{|l|}{ Geographical region } \\
\hline East Midlands & 216535 & $14004(6.47)$ & $6016(2.78)$ \\
\hline East of England & 296236 & $24270(8.19)$ & $11998(4.05)$ \\
\hline London & 2080923 & $112569(5.41)$ & $58961(2.83)$ \\
\hline North East & 194027 & $17597(9.07)$ & $6370(3.28)$ \\
\hline North West & 1471787 & $137043(9.31)$ & $61705(4.19)$ \\
\hline South Central & 1104114 & $89462(8.10)$ & $42668(3.86)$ \\
\hline South East & 927208 & $79871(8.61)$ & $43932(4.74)$ \\
\hline South West & 899722 & $75767(8.42)$ & $32850(3.65)$ \\
\hline West Midlands & 781297 & $70613(9.04)$ & $33605(4.3)$ \\
\hline Yorkshire and Humber & 304100 & $24381(8.02)$ & $10776(3.54)$ \\
\hline \multicolumn{4}{|l|}{ Smoking status } \\
\hline Never smoker & 4745455 & $335769(7.08)$ & $181411(3.82)$ \\
\hline Ex-smoker & 1774275 & $227398(12.82)$ & $103363(5.83)$ \\
\hline Light smoker & 1109154 & $62039(5.59)$ & $18364(1.66)$ \\
\hline Moderate smoker & 213629 & $11542(5.40)$ & $3332(1.56)$ \\
\hline Heavy smoker & 98748 & 7929 (8.03) & $2011(2.04)$ \\
\hline Smoking not recorded & 334688 & $900(0.27)$ & $400(0.12)$ \\
\hline \multicolumn{4}{|l|}{ Body mass index (BMI) } \\
\hline $\mathrm{BMI}<20 \mathrm{~kg} / \mathrm{m}^{2}$ & 543347 & $13050(2.40)$ & $5153(0.95)$ \\
\hline BMI $20-24.99 \mathrm{~kg} / \mathrm{m}^{2}$ & 2438268 & $115952(4.76)$ & $50968(2.09)$ \\
\hline BMI $25-29.99 \mathrm{~kg} / \mathrm{m}^{2}$ & 2344187 & $231282(9.87)$ & $109202(4.66)$ \\
\hline BMI $30-34.99 \mathrm{~kg} / \mathrm{m}^{2}$ & 1090042 & $158175(14.51)$ & $79933(7.33)$ \\
\hline BMI $35+\mathrm{kg} / \mathrm{m}^{2}$ & 619487 & $108568(17.53)$ & $55489(8.96)$ \\
\hline BMI not recorded & 1240618 & $18550(1.50)$ & $8136(0.66)$ \\
\hline \multicolumn{4}{|l|}{ Concurrent morbidity } \\
\hline Chronic renal disease & 338693 & $103643(30.60)$ & $65255(19.27)$ \\
\hline Asthma & 1089645 & $83948(7.70)$ & $4927(4.52)$ \\
\hline COPD & 195115 & $43288(22.19)$ & $21063(10.80)$ \\
\hline Cardiovascular disease & 433631 & $165415(38.15)$ & $71472(16.48)$ \\
\hline Atrial fibrillation & 201911 & $61332(30.38)$ & $32330(16.01)$ \\
\hline
\end{tabular}

Continued 


\begin{tabular}{|c|c|c|c|}
\hline Category & $\begin{array}{l}\text { Number in } \\
\text { category }\end{array}$ & $\begin{array}{l}\text { Prescribed ACE } \\
\text { inhibitor (row \%) }\end{array}$ & $\begin{array}{l}\text { Prescribed ARB } \\
\text { (row \%) }\end{array}$ \\
\hline Congestive cardiac failure & 97118 & $43746(45.04)$ & $21637(22.28)$ \\
\hline Type 1 diabetes & 39094 & $8316(21.27)$ & $2989(7.65)$ \\
\hline Type 2 diabetes & 536516 & $193155(36.00)$ & 88308 (16.46) \\
\hline Hypertension diagnosis & 1414021 & $536002(37.91)$ & $274784(19.43)$ \\
\hline Monotherapy & 773675 & $230565(29.80)$ & 105921 (13.69) \\
\hline Dual therapy & 516178 & $293187(56.80)$ & $138397(26.81)$ \\
\hline Triple therapy & 190856 & $121825(63.83)$ & $64563(33.83)$ \\
\hline \multicolumn{4}{|l|}{ Long-term medication } \\
\hline ACE inhibitor & 645577 & & $4119(0.64)$ \\
\hline ARB & 308881 & $4119(1.33)$ & \\
\hline Beta-blockers & 525149 & $189691(36.12)$ & $86126(16.40)$ \\
\hline Calcium channel blockers & 654171 & $241203(36.87)$ & $119143(18.21)$ \\
\hline Other diabetes drugs & 151074 & $65933(43.64)$ & 29245 (19.36) \\
\hline Sulfonylureas & 98908 & $43836(44.32)$ & $18591(18.80)$ \\
\hline Biguanides & 328387 & $135263(41.19)$ & $57509(17.51)$ \\
\hline Anticoagulants & 207061 & $66374(32.06)$ & 33889 (16.37) \\
\hline Antiplatelets & 410816 & $169770(41.33)$ & $73938(18.00)$ \\
\hline Statins & 1073039 & $388769(36.23)$ & $173983(16.21)$ \\
\hline Thiazides & 220143 & $96311(43.75)$ & $55142(25.05)$ \\
\hline Potassium-sparing diuretics & 46825 & $20660(44.12)$ & $11807(25.22$ \\
\hline
\end{tabular}

$\mathrm{ARB}$, angiotensin receptor blocker; $\mathrm{COPD}$, chronic obstructive pulmonary disease. had an increased risk of COVID-19 disease and ICU admission. There were regional variations in the risk of COVID-19 disease and ICU admission, the South West had the lowest risk of both outcomes, the North East had the highest risk of COVID-19 disease and London had the highest risk of ICU admission.

Overall, compared with the white ethnic group, all other ethnic groups except Chinese and Bangladeshi groups were associated with a significantly increased risk of COVID-19 disease. Highest risks were found for the other Asian group who had a 2.1-fold increased risk; Black African (1.8-fold increased risk); Black Caribbean (1.71-fold increased risk) and Indian (1.61-fold increased risk) compared with the white group. The comparative risk of ICU admission in these ethnic groups was even higher. Compared with the white group, all other ethnic groups had twofold to threefold higher risks of ICU admission, but smaller numbers of people in these groups led to some imprecise estimates.

\section{Association of each outcome with category of body mass index}

The risks of COVID-19 disease and of ICU admission were higher in those with increasing BMI. The most pronounced gradient was for ICU admission, where being obese was associated with a 2.6-fold increased risk and severe obesity with a 4.4fold increased risk compared with the normal weight group. This was after adjustment for all other variables shown in figure $1 \mathrm{~B}$.
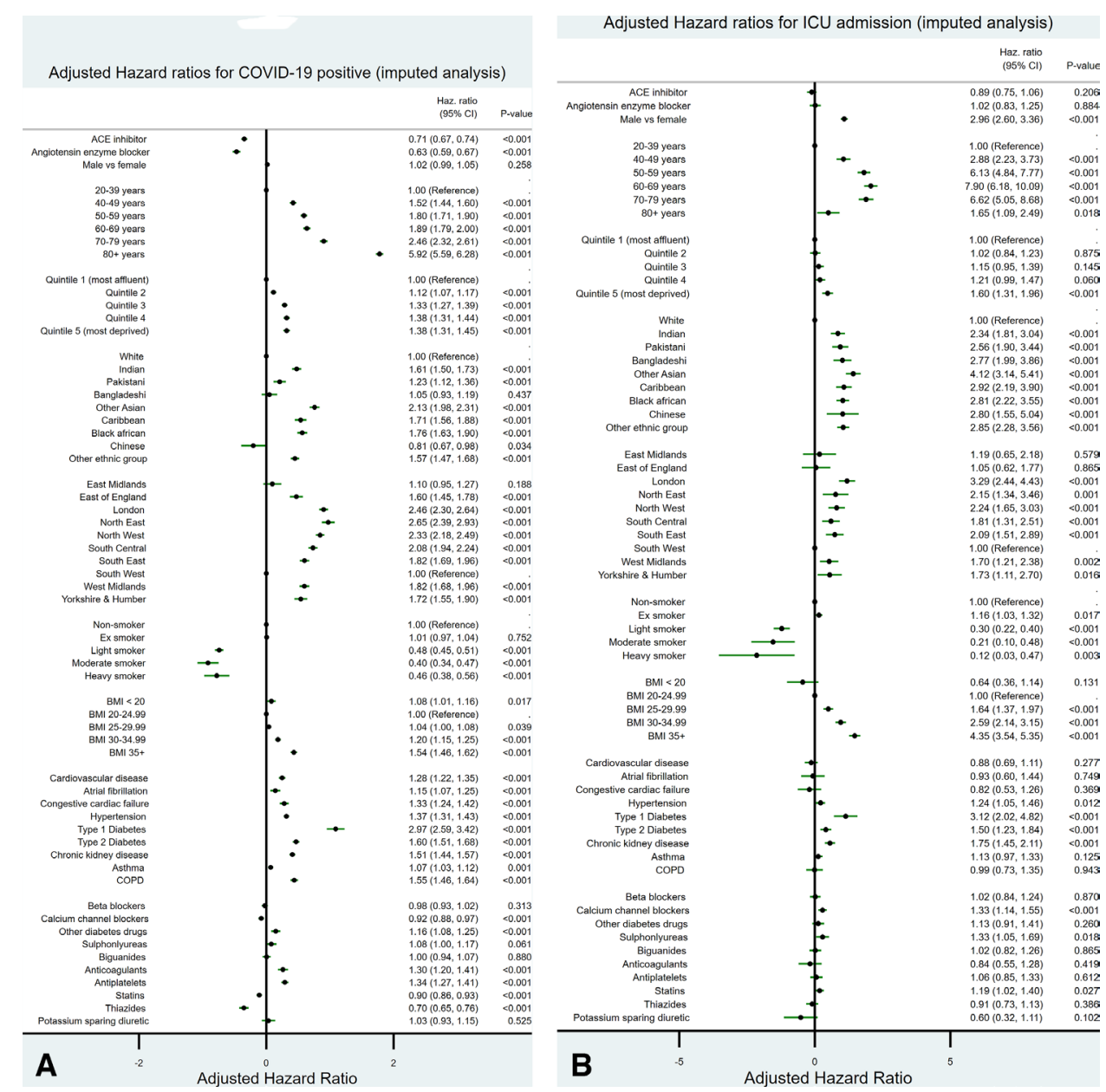

Figure 1 The adjusted HRs along with $95 \%$ Cls for (A) the outcome of a positive COVID-19 RT-PCR test and (B) the outcome of admission to an intensive care unit (ICU), for all the variables studied based on multiple imputed data. BMI, body mass index; COPD, chronic obstructive pulmonary disease. 

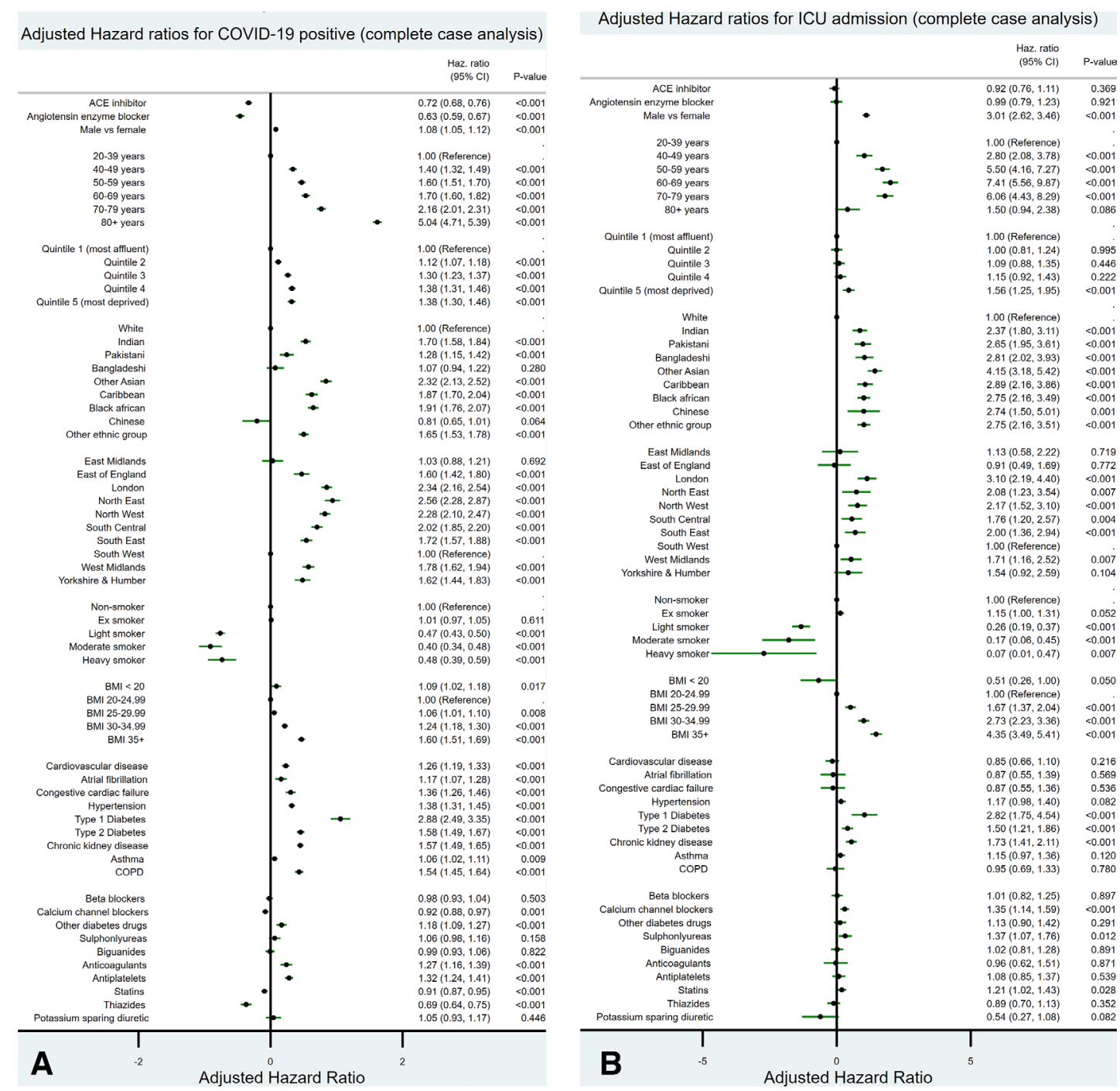

Figure 2 The adjusted HRs along with $95 \%$ Cls for (A) the outcome of a positive COVID-19 RT-PCR test and (B) the outcome of admission to an intensive care unit (ICU), for all the variables studied based on the completed case analysis. BMI, body mass index; COPD, chronic obstructive pulmonary disease.

\section{Association of each outcome with smoking status}

There was a small increased risk of both adverse outcomes among ex-smokers compared with never-smokers. We observed a markedly decreased risk of both COVID-19 disease and ICU admission in smokers. The apparent protective association was greatest for heavy and moderate smokers and most markedly on the risk of ICU admission which was $88 \%$ lower in heavy smokers compared with non-smokers (figure 1B).

\section{Association of each outcome with comorbidity and concurrent medication}

Each of the comorbidities included in the analysis was associated with an increased risk of COVID-19 disease. However, only CKD, hypertension, type 1 and type 2 diabetes were significantly associated with an increased risk of ICU admission.

Figure 1A shows significantly increased risks of COVID-19 disease associated with anticoagulants, antiplatelets, other diabetes drugs; significantly decreased risks of $10 \%$ for statins, $30 \%$ for thiazides and $8 \%$ for calcium channel blockers and no significant association for biguanides, beta-blockers or sulfonylureas. For ICU admission there was a significantly increased risk for calcium channel blockers, but no significant associations with the other drugs (at $\mathrm{p}<0.01)$.

\section{DISCUSSION}

\section{Summary of key results}

In this very large population-based study, ACE inhibitor and ARB prescriptions were associated with a reduced risk of COVID-19 RT-PCR positive disease, having adjusted for a wide range of demographic factors, potential comorbidities and other medication. There was no evidence of an increased or reduced risk of ICU admission with either drug.

There were marked variations in risk of COVID-19 disease and of requiring ICU admission by ethnic group, with highest rates among Black, Asian, and minority ethnic (BAME) groups. This association is important and adds to existing knowledge ${ }^{18}$ since it is not explained by age, sex, deprivation, geographical region or several comorbidities and intercurrent medications included in our analysis.

\section{Comparisons with the literature}

To date, published studies reporting associations between chronic medication with ACE inhibitor or ARB drugs and COVID-19 
Table 3 Adjusted HRs ( $95 \% \mathrm{Cl}$ ) for risk of COVID-19 positive test associated with ACE inhibitor and ARB exposure by ethnic group

\begin{tabular}{|c|c|c|c|c|}
\hline & \multirow{2}{*}{$\begin{array}{l}\text { ACE inhibitor } \\
\text { Adjusted HR } \\
(95 \% \mathrm{Cl})\end{array}$} & \multirow[b]{2}{*}{$P$ value } & \multirow{2}{*}{$\begin{array}{l}\text { ARB } \\
\text { Adjusted HR } \\
(95 \% \mathrm{Cl}) \\
\end{array}$} & \multirow[b]{2}{*}{$P$ value } \\
\hline & & & & \\
\hline White & $\begin{array}{l}0.66 \text { ( } 0.63 \text { to } \\
0.70)\end{array}$ & $<0.001$ & $\begin{array}{l}0.56 \text { ( } 0.52 \text { to } \\
0.62)\end{array}$ & $<0.001$ \\
\hline Indian & $\begin{array}{l}0.74 \text { ( } 0.61 \text { to } \\
0.90)\end{array}$ & 0.003 & $\begin{array}{l}0.66 \text { ( } 0.52 \text { to } \\
0.82)\end{array}$ & $<0.001$ \\
\hline Pakistani & $\begin{array}{l}0.83 \text { (0.64 to } \\
1.09)\end{array}$ & 0.182 & $\begin{array}{l}0.78 \text { (0.57 to } \\
1.06)\end{array}$ & 0.114 \\
\hline Bangladeshi & $\begin{array}{l}0.97(0.72 \text { to } \\
1.31)\end{array}$ & 0.847 & $\begin{array}{l}0.74 \text { ( } 0.49 \text { to } \\
1.13)\end{array}$ & 0.164 \\
\hline Other Asian & $\begin{array}{l}0.81 \text { (0.64 to } \\
1.03)\end{array}$ & 0.084 & $\begin{array}{l}0.96 \text { ( } 0.73 \text { to } \\
1.23)\end{array}$ & 0.726 \\
\hline Caribbean & $\begin{array}{l}1.05 \text { (0.87 to } \\
1.28)\end{array}$ & 0.480 & $\begin{array}{l}0.70 \text { (0.53 to } \\
0.92)\end{array}$ & 0.010 \\
\hline Black African & $\begin{array}{l}1.31 \text { (1.08 to } \\
1.59)\end{array}$ & 0.005 & $\begin{array}{l}1.24 \text { (0.99 to } \\
1.58)\end{array}$ & 0.062 \\
\hline Chinese & $\begin{array}{l}0.73(0.30 \text { to } \\
1.79)\end{array}$ & 0.575 & $\begin{array}{l}1.53 \text { (0.77 to } \\
3.01)\end{array}$ & 0.223 \\
\hline Other ethnic group & $\begin{array}{l}0.82 \text { (0.67 to } \\
1.05)\end{array}$ & 0.122 & $\begin{array}{l}1.09 \text { ( } 0.86 \text { to } \\
1.39)\end{array}$ & 0.475 \\
\hline
\end{tabular}

HRs are comparing risks of COVID-19 in users versus non-users of ACE inhibitor and ARB, and are adjusted for age, sex, deprivation, geographical region, comorbidities (including hypertension included as a binary variable) and other medications listed in table 1.

$A R B$, angiotensin receptor blocker.

infections are limited to hospitalised patients ${ }^{6} 101119$ or those attending a hospital clinic. ${ }^{20}$ This allows the study of drug treatment effects on the in-hospital disease course but not effects on disease susceptibility since there is no information on medication use in the uninfected or less severely infected population. Most in-hospital studies are relatively small containing low numbers of patients or ACE inhibitors of ARBs in comparison to our study. However, two ${ }^{619}$ were able to correct for the confounding effects of age, gender, comorbidities and in-hospital medications. In one study of 1128 patients with hypertension of whom 188 were taking ACE inhibitors/ARB, ${ }^{6}$ in-hospital use of ACE inhibitor or ARB medication was associated with a lower risk of all-cause in-hospital mortality (adjusted HR 0.42; 95\% CI 0.19 to $0.92 ; \mathrm{p}=0.03$ ). In the larger 8910 patient study (770 taking ACE inhibitors and 556 ARBs), ACE inhibitors were associated with reduced in-hospital mortality $(2.1 \%$ vs $6.1 \%$; OR 0.33 ; $95 \% \mathrm{CI} 0.20$ to 0.54$)$ but $\mathrm{ARBs}$ were not $(6.8 \%$ vs $5.7 \%$; OR $1.23 ; 95 \%$ CI 0.87 to 1.74$).{ }^{19}$ Conversely, there was no evidence of reduced risk in outcomes in patients receiving ACE inhibitor and ARB drugs in initial reports from New York. ${ }^{11}$

In our study, prior prescription of ACE inhibitor and ARB drugs did not have a significant effect on the risk of patients developing COVID-19 disease severe enough to require ICU care. In contrast, we found that previously prescribed ACE inhibitor and ARB drugs are associated with the likelihood of an individual testing positive for COVID-19 in a hospital setting. The effect was similar for both drug classes. This may indicate that drug treatment at the time of exposure altered susceptibility to COVID-19 infection and/or altered the likelihood of an infection progressing to the point where testing is sought. It is also possible that this reflects a 'healthy user' selection bias. There are no other population-based studies of ACE inhibitor/ARB use and COVID-19 infection. Losartan is already being tested in a clinical trial as a treatment of COVID-19 infection. ${ }^{21}$ Its efficacy may depend on the context in which it is tested. Since the recommendations for treatment of hypertension differ according to ethnic groups and age, we considered the possibility that these factors might contribute to the observed association between ACE inhibitor or ARB use and COVID-19 disease or severity. ACE inhibitors are recommended as first-line treatment for hypertension, whereas calcium channel blockers are recommended in patients of black ethnic origin. ${ }^{8}$ Indeed, there were significant interactions between ethnicity, ACE inhibitor and ARBs for COVID-19 disease. ARBs were significantly less protective in the other Asian, Black African, Chinese and other ethnic group than the white group. ACE inhibitors appeared less protective in the Caribbean than the white group and were associated with an increased risk of COVID-19 disease in the Black African group. This raises the possibility of ethnic-specific effects of ACE inhibitors/ARBs on COVID-19 disease susceptibility and severity or unmeasured confounding. However, as numbers were relatively small in the non-white ethnic groups so CIs were wide, caution is needed in interpreting these results.

Studies of patients hospitalised with COVID-19 have noted a greater than expected number of patients with hypertension, ${ }^{2}$ and hypertension appears to be a risk factor for more severe COVID-19 disease across many studies. ${ }^{4}$ In our study, hypertension was a risk factor for being tested positive for COVID-19 in a hospital setting independent of ACE inhibitor and ARB treatment, but was only modestly associated with likelihood of ICU admission. We found an expected association with obesity, with those who are obese or severely obese having higher risk of COVID-19 disease and ICU admission. However, we have reported a counterintuitive finding for smoking, with light, moderate and heavy smokers having a lower risk for both COVID-19 disease and ICU admission. One systematic review concluded on the basis of limited evidence either there is no difference in risk by smoking status or that there is an increased risk in smokers. ${ }^{22}$ However, our data are consistent with very low rates of smoking seen in patients presenting with COVID-19 in Wuhan ${ }^{23}$ and similar data from the USA ${ }^{24}$ and with the findings of a more limited analysis of patients with COVID-19 in France. ${ }^{25}$ This may reflect a general immunomodulatory effect, a mechanism that is thought to explain the lower incidence of sarcoidosis, extrinsic allergic alveolitis and ulcerative colitis in current smokers. ${ }^{26}{ }^{27}$ Alternatively, smoking may cause increased ACE2 mRNA expression in human lung much as ACE inhibitors or ARBs are believed to, suggesting a possible common protective mechanism for severe COVID-19 disease. ${ }^{28}$ Additional possible mechanisms include a direct protective effect of nicotinic receptor stimulation ${ }^{29}$ or an association of smoking with another protective factor. This finding arose when including smoking status as a confounder and should be interpreted cautiously. Further studies are required to verify the apparent protective association, determine whether it is independent of other risk factors, and investigate potential mechanisms.

\section{Strengths}

We have used two high-quality, established large validated research databases (QResearch and ICNARC CMP) and linked them to the national register of COVID-19 test results. Our study is observational with strengths and inherent limitations since the data were collected as part of routine NHS care. Key strengths include the use of highquality, established validated databases, size, representativeness, lack of selection, recall and respondent bias. UK general practices have good levels of accuracy and completeness in recording clinical diagnoses and prescriptions and provide the ability to update analyses as data change over time..$^{30}$ It is therefore likely to be representative of the population of England. It has good face validity since it has been conducted in the setting where most patients in the UK are assessed, treated and followed up. We have been able to adjust for a wide 
range of confounders based on detailed coded information recorded in the patients' electronic medical record.

We restricted the sample for these analyses to only include patients with hypertension or heart failure so that all patients, whether treated with ACE inhibitors/ARBs or not, had the same indication for treatment. This is an important additional analysis as hypertension and heart failure themselves are associated with adverse COVID-19 outcomes, and this restricted analysis reduces their confounding effect and allows for a more direct comparison of the antihypertensive drugs in people with indications for their use. We also accounted for ethnicity and other confounding variables in this restricted analysis which could influence the selection of an antihypertensive treatment and also be associated with COVID-19 outcomes. Some systematic differences are still likely between patients who are treated and those who are not, such as severity of hypertension. We have carried out an additional analysis where we adjusted for a proxy measure of severity.

\section{Limitations}

There may be some over-ascertainment of exposure to medication since our definition was based on issued prescriptions rather than dispensed medication. Our analyses focused on drug classes rather than individual drugs as there were insufficient cases to support an analysis at individual drug level. We have not investigated the relationship between the intensity and duration of exposure and the risk of disease in this early analysis. We investigated the more mechanistically likely and therefore immediately clinically important drug associations. Other drug classes can be investigated as numbers accrue. Data on community and care home deaths or deaths occurring within hospital but not in ICU are not yet available from Hospital Episode Statistics and Civil Registrations. Linkage of the GP data to national registries of outcome data, updated in near real time, will have

\section{Key messages}

\section{What is already known on this subject?}

- There is uncertainty about the interaction of ACE inhibitor and angiotensin receptor blocker (ARB) drugs with COVID-19 disease susceptibility and disease severity.

\section{What might this study add?}

- In this very large population-based study, treatment with ACE inhibitor and ARB prescriptions is associated with a reduced risk of COVID-19 RT-PCR positive disease after adjusting for a wide range of variables.

- Neither ACE inhibitors nor ARBs are associated with increased risks of receiving ICU care for COVID-19 disease.

- There are significant interactions with ethnicity for ACE inhibitors and ARBs for COVID-19 disease with higher risks among the non-white ethnic groups particularly Black African patients compared with the white group, although the confidence intervals for some analyses are wide; this finding is important and adds to existing knowledge.

\section{How might this impact on clinical practice?}

- Neither ACE inhibitors nor ARBs are associated with increased risks of COVID-19 RT-PCR positive disease or of receiving ICU care for COVID-19 disease.

- Variations between different ethnic groups raise the possibility of ethnic-specific effects of ACE inhibitors/ARBs on COVID-19 disease susceptibility and severity which deserves further study. minimised ascertainment bias relating to laboratory confirmed cases. However, there will be underascertainment of total COVID-19 cases due to the current absence of widespread systematic testing strategy in the UK, and due to false negative tests. As UK health policy during the study period confined testing for COVID-19 to hospitalised patients, our data focus on the incidence of more severe disease, rather than all cases, as most people with probable COVID-19 are not admitted to hospital. Some patients deemed to be at high risk of adverse outcomes of COVID-19 will have self-isolated during our study period to reduce their risk of contracting the virus and if effective, may result in a selection bias with such patients less likely to be become infected and subsequently admitted to hospital or ICU. Not all acutely unwell patients in hospital are admitted to ICU and this may result in a selection bias. Admission to ICU is limited to those who might benefit from this treatment and so varies on the basis of patient demographic and medical characteristics. Data on deaths in ICU were available to us but a significant proportion of patients admitted to an ICU were still being treated in an ICU and this varied by region as the pandemic spread. For this reason, ICU deaths were not included in the analysis. Further analyses of mortality will be undertaken once the relevant data (including out-of-hospital deaths) become available.

We have undertaken two new novel data linkages by linking QResearch to both COVID-19 test results and outcomes recorded on the ICNARC CMP data. This new linked data asset is a valuable resource for future research projects.

\section{CONCLUSION}

In this very large population-based study, ACE inhibitor and ARB prescriptions were associated with a reduced risk of COVID-19 RT-PCR positive disease in a hospital setting adjusting for a wide range of demographic factors, potential comorbidities and other medication. There was no evidence of an increased or decreased risk associated with either drug for ICU admission. There are marked variations in risk of COVID-19 disease and ICU admission by ethnic group, with highest rates among BAME groups. The strength of this association is greater with the more severe outcome and is not explained by age, sex, deprivation, geographical region or several comorbidities and intercurrent medications included in the analysis. The counterintuitive finding of smokers having a lower risk of COVID-19 disease requiring hospital admission and ICU admission deserves further study.

\section{Author affiliations}

${ }^{1}$ Primary Care Health Sciences, University of Oxford, Oxford, UK

${ }^{2}$ Adult Intensive Care Unit, John Radcliffe Hospital, Oxford, UK

${ }^{3}$ Kadoorie Centre, University of Oxford, Oxford, UK

${ }^{4}$ Division of Primary Care, School of Medicine, University of Nottingham, Nottingham, UK

${ }^{5}$ Division of Cardiovascular Medicine, British Heart Foundation Centre of Research Excellence, John Radcliffe Hospital, University of Oxford, Oxford, UK

${ }^{6}$ Nuffield Department of Primary Care Health Sciences, University of Oxford, Oxford, UK

${ }^{7}$ Clinical Trials Unit, ICNARC, London, UK

${ }^{8}$ Intensive Care National Audit and Research Centre ICNARC, London, UK

${ }^{9}$ Respiratory Medicine Unit and Oxford Respiratory NIHR BRC Nuffield Department of MedicineNDM Research BuildingOld Road CampusUniversity of Oxford, Oxford, UK

${ }^{10}$ Nuffield Department of Clinical Neurosciences, Oxford NIHR BRC, University of Oxford, Oxford, UK

\section{Twitter Julia Hippisley-Cox @juliahcox}

Acknowledgements The authors acknowledge the contribution of Egton Medical Information Systems (EMIS) practices who contribute to the QResearch database and EMIS, and the Universities of Nottingham and Oxford for expertise in establishing, developing and supporting the QResearch database. QResearch acknowledges funding from the NIHR-funded Oxford Biomedical Research Centre. The data on 
COVID-19 PCR tests were used with permission from Public Health England. The intensive care data were used with permission from ICNARC.

Contributors JHC contributed to the inception of the study, development of study ideas, study design acquisition and linkage of data, undertook the data analysis, wrote the first draft of the paper. DY and PJW contributed to the inception of the study, development of the study ideas, study design, advised on the interpretation of the results and drafting of the paper. CC contributed to the study design and advised on the analysis, advised on the interpretation of the results and drafting of the paper. PST contributed to the literature review, classification of drugs, interpretation of the results and critically reviewed the paper. KC, PA and IDP critically reviewed the paper. All authors have approved the submitted version. The corresponding author attests that all listed authors meet authorship criteria and that no others meeting the criteria have been omitted.

Funding This study was supported by funds from the NIHR Oxford Biomedical Research Centre and the Medical Sciences Division of the University of Oxford. QResearch is funded by the John Fell Oxford University Press Research Fund, the Oxford Wellcome Institutional Strategic Support Fund (204826/Z/16/Z), Cancer Research UK (CR-UK) grant number C5255/A18085, through the Cancer Research UK Oxford Centre and the Wellcome Trust (grant number is 221514/Z/20/Z). It also receives contributions in kind from EMIS Health (commercial supplier of NHS health computer systems). KC is supported by the British Heart Foundation (CH/16/1/32013). PA is an NIHR senior investigator and funded by NIHR Oxford Biomedical Research Centre and Applied Research Centre. JH is the guarantor of the study and had full access to all the data in the study and had final responsibility for the decision to submit for publication.

Competing interests $\mathrm{JHC}$ reports grants from National Institute for Health Research Biomedical Research Centre, Oxford, grants from John Fell Oxford University Press Research Fund, grants from Cancer Research UK (CR-UK) grant number C5255/A18085, through the Cancer Research UK Oxford Centre, grants from the Oxford Wellcome Institutional Strategic Support Fund (204826/Z/16/Z) during the conduct of the study; personal fees and other from ClinRisk Ltd (until 2019) outside the submitted work; and JH is an unpaid director of QResearch, a not-for-profit organisation which is a partnership between the University of Oxford and EMIS Health who supply the QResearch database used for this work. PW reports grants from National Institute for Health Research Biomedical Research Centre, Oxford and the Wellcome Trust (grant number is 221514/Z/20/Z), during the conduct of the study; grants from Sensyne Health, personal fees from Sensyne Health, outside the submitted work. PST reports consulting with AstraZeneca and Duke-NUS outside the submitted work. IDP reports personal fees from AstraZeneca, personal fees from Boehringer Ingelheim, personal fees from Aerocrine, personal fees from Almirall, personal fees from Novartis, personal fees from GlaxoSmithKline, personal fees from Genentech, personal fees from Regeneron, Teva, Chiesi, Sanofi, Circassia, Knopp, grants from NIHR, outside the submitted work. DY, CC, PA, DAH, KR, KC have nothing to disclose.

Patient and public involvement Patients and/or the public were involved in the design, conduct, reporting or dissemination plans of this research. Refer to the 'Methods' section for further details.

Patient consent for publication Not required.

Provenance and peer review Not commissioned; externally peer reviewed.

Data availability statement Data may be obtained from a third party and are not publicly available. To guarantee the confidentiality of personal and health information only the authors have had access to the data during the study in accordance with the relevant licence agreements. Access to the QResearch data is according to the information on the QResearch website (www.qresearch.org). ICNARC data were provided under a licence that does not permit sharing.

Open access This is an open access article distributed in accordance with the Creative Commons Attribution 4.0 Unported (CC BY 4.0) license, which permits others to copy, redistribute, remix, transform and build upon this work for any purpose, provided the original work is properly cited, a link to the licence is given, and indication of whether changes were made. See: https://creativecommons.org/ licenses/by/4.0/.

\section{ORCID iDs}

Julia Hippisley-Cox http://orcid.org/0000-0002-2479-7283

David A Harrison http://orcid.org/0000-0002-9002-9098

Peter J Watkinson http://orcid.org/0000-0003-1023-3927

\section{REFERENCES}

1 Ledford H. Hopes rise for coronavirus drug remdesivir. Nature 2020. doi:10.1038/ d41586-020-01295-8. [Epub ahead of print: 29 Apr 2020].
2 Garg S, Kim L, Whitaker M, et al. Hospitalization Rates and Characteristics of Patients Hospitalized with Laboratory-Confirmed Coronavirus Disease 2019 - COVID-NET, 14 States, March 1-30, 2020. MMWR Morb Mortal Wkly Rep 2020;69:458-64.

3 Piva S, Filippini M, Turla F, et al. Clinical presentation and initial management critically ill patients with severe acute respiratory syndrome coronavirus 2 (SARS-CoV-2) infection in Brescia, Italy. J Crit Care 2020;58:29-33.

4 Wang B, Li R, Lu Z, et al. Does comorbidity increase the risk of patients with COVID-19: evidence from meta-analysis. Aging 2020;12:6049-57.

5 Pareek M, Bangash MN, Pareek N, et al. Ethnicity and COVID-19: an urgent public health research priority. Lancet 2020;395:1421-2.

6 Zhang P, Zhu L, Cai J, et al. Association of inpatient use of angiotensinconverting enzyme inhibitors and angiotensin II receptor blockers with mortality among patients with hypertension hospitalized with COVID-19. Circ Res 2020;126:1671-81.

7 Vaduganathan M, Vardeny O, Michel T, et al. Renin-Angiotensin-Aldosterone system inhibitors in patients with Covid-19. N Eng/ J Med 2020;382:1653-9.

8 National Institute for Clinical Excellence. Hypertension in adults: diagnosis and management NICE guideline [NG136]. London NICE; 2019.

9 European Society of Cardiology. Position statement of the ESC Council on hypertension on ACE-inhibitors and angiotensin receptor blockers; 2020.

10 Li J, Wang X, Chen J, et al. Association of renin-angiotensin system inhibitors with severity or risk of death in patients with hypertension hospitalized for coronavirus disease 2019 (COVID-19) infection in Wuhan, China. JAMA Cardiol 2020. doi:10.1001/jamacardio.2020.1624. [Epub ahead of print: 23 Apr 2020].

11 Richardson S, Hirsch JS, Narasimhan M, et al. Presenting characteristics, comorbidities, and outcomes among 5700 patients hospitalized with COVID-19 in the new York City area. JAMA 2020. doi:10.1001/jama.2020.6775. [Epub ahead of print: 22 Apr 2020]

12 Hippisley-Cox JYD, Coupland C, Harrison D, et al. Coronavirus Record Linkage Project - QResearch-ICNARC COVID-19 Collaboration 2020.

13 Coupland CAC, Hill T, Dening T, et al. Anticholinergic drug exposure and the risk of dementia: a nested case-control study. JAMA Intern Med 2019;179:1084-93.

14 Kontopantelis E, Stevens RJ, Helms PJ, et al. Spatial distribution of clinical computer systems in primary care in England in 2016 and implications for primary care electronic medical record databases: a cross-sectional population study. BMJ Open 2018;8:e20738.

15 Damian MS, Ben-Shlomo Y, Howard R, et al. Admission patterns and survival from status epilepticus in critical care in the UK: an analysis of the intensive care national audit and research centre case mix programme database. Eur J Neurol 2020;27:557-64.

16 Ferrando-Vivas $\mathrm{P}$, Jones $\mathrm{A}$, Rowan $\mathrm{KM}$, et al. Development and validation of the new ICNARC model for prediction of acute hospital mortality in adult critical care. J Crit Care 2017:38:335-9.

17 Steyerberg EW, van Veen M. Imputation is beneficial for handling missing data in predictive models. J Clin Epidemiol 2007;60:979.

18 Public Health England. Disparities in the risk and outcomes of COVID-19 2020.

19 Mehra MR, Desai SS, Kuy S, et al. Cardiovascular disease, drug therapy, and mortality in Covid-19. N Eng/ J Med Overseas Ed 2020;382:NEJMc2021225:e102.

20 Mehta N, Kalra A, Nowacki AS, et al. Association of use of angiotensin-converting enzyme inhibitors and angiotensin II receptor blockers with testing positive for coronavirus disease 2019 (COVID-19). JAMA Cardiol 2020.

21 Trials C. Losartan for patients with COVID-19 not requiring hospitalization, 2020. Available: https://clinicaltrials.gov/ct2/show/NCT04311177

22 Berlin I, Thomas D, Le Faou A-L, et al. COVID-19 and smoking. Nicotine Tob Res 2020. doi:10.1093/ntr/ntaa059. [Epub ahead of print: 03 Apr 2020].

23 Guan W-J, Ni Z-Y, Hu Y, et al. Clinical characteristics of coronavirus disease 2019 in China. N Engl J Med 2020;382:1708-20.

24 CDC COVID-19 Response Team. Preliminary Estimates of the Prevalence of Selected Underlying Health Conditions Among Patients with Coronavirus Disease 2019 - United States, February 12-March 28, 2020. MMWR Morb Mortal Wkly Rep 2020;69:382-6.

25 Miyara MTF, POURCHER V, Morelot-Panzini C, et al. Low incidence of daily active tobacco smoking in patients with symptomatic COVID-19. Qeios 2020.

26 Guslandi M. Nicotine treatment for ulcerative colitis. Br I Clin Pharmacol 1999:48:481-4.

27 Maier LA. Is smoking beneficial for granulomatous lung diseases? Am J Respir Crit Care Med 2004;169:893-5.

28 Cai G, Bossé Y, Xiao F, et al. Tobacco smoking increases the lung gene expression of ACE2, the receptor of SARS-CoV-2. Am J Respir Crit Care Med 2020;201:1557-9.

29 CHANGEUX jean-pierre, Amoura Z, Rey F, et al. A nicotinic hypothesis for Covid-19 with preventive and therapeutic implications. Qeios 2020.

30 Majeed A. Sources, uses, strengths and limitations of data collected in primary care in England. Health Stat Q 2004:21:5-14. 